\title{
Surgical Management of Deep Brain Stimulator Infection without Electrode Removal: Report of Two Cases
}

\author{
Hiroaki Tanaka ${ }^{1}$ Hideaki Rikimaru ${ }^{1}$ Yukiko Rikimaru-Nishi ${ }^{1,2}$ Norihiro Muraoka ${ }^{3,4}$ Mina Anegawa ${ }^{1}$ \\ Shoya Ueki ${ }^{1}$ Ou Oishi ${ }^{1,5}$ Kensuke Kiyokawa ${ }^{1}$
}

\footnotetext{
${ }^{1}$ Department of Plastic and Reconstructive Surgery and Maxillofacial Surgery, Kurume University School of Medicine, Kurume-shi, Fukuoka, Japan

2 Division of Microscopic and Developmental Anatomy, Department of Anatomy, Kurume University School of Medicine, Kurume-shi, Fukuoka, Japan

${ }^{3}$ Department of Neurological Surgery, National Center Hospital of Neurology and Psychiatry, Kodaira-shi, Tokyo, Japan

${ }^{4}$ Department of Neurological Surgery, Takagi Hospital, Okawa-shi, Fukuoka, Japan

${ }^{5}$ Department of Plastic and Reconstructive Surgery, Takagi Hospital, Okawa-shi, Fukuoka, Japan
}

\begin{abstract}
Address for correspondence Hideaki Rikimaru, MD, PhD, Department of Plastic and Reconstructive Surgery, and Maxillofacial Surgery, Kurume University School of Medicine, 67 Asahi-machi, Kurume, Fukuoka 830-0011, Japan (e-mail: Hi_rikimaru@yahoo.co.jp).
\end{abstract}

J Neurol Surg Rep 2020;81:e15-e19.

\author{
Abstract \\ Keywords \\ - deep brain \\ stimulation \\ - electrode lead \\ - infection \\ - intractable wound \\ - cutaneous fistula \\ - intrawound \\ continuous negative \\ pressure and \\ irrigation therapy \\ - reconstruction \\ - pericranial flap \\ - scalp flap
}

Objective Stimulation of the subthalamic nucleus by implanted electrodes (deep brain stimulation [DBS]) is performed to suppress symptoms of Parkinson's disease. However, postoperative wound dehiscence and infection can require removal of the implanted electrode leads. This report describes treatment of intractable unilateral wound infection in two patients without removing the DBS device.

Methods First, components of the DBS system were removed except for the electrode lead and thorough debridement of the infected wound was conducted. Second, the edges of the bone defect left by removal of DBS components were smoothed to eliminate dead space. Subsequently, the electrode lead was covered by using a pericranial-frontalis-muscle flap or a bi-pedicled-scalp flap with good blood supply. Closed intrawound continuous negative pressure and irrigation treatment was conducted for 1 week after the surgery, and then the drain was removed.

Results We treated two patients with wound infection after implantation of DBS electrodes. Case 1 developed a cutaneous fistula and Case 2 had wound dehiscence. After treatment by the method described above, complete wound healing was achieved in both patients.

Conclusion DBS is always associated with a risk of infection or exposure of components and treatment can be very difficult. We successfully managed intractable wound infection while leaving the electrode lead in situ, so that it was subsequently possible to continue DBS for Parkinson's disease. received

May 14, 2019

accepted after revision

September 28, 2019
DOI https://doi.org/

10.1055/s-0039-3399569.

ISSN 2193-6358. (c) 2020 Georg Thieme Verlag KG
Stuttgart · New York

License terms

(c) $(1) \$$ 


\section{Introduction}

Deep brain stimulation (DBS) therapy involves electrical stimulation of the subthalamic nucleus and the globus pallidus, and it is widely used for Parkinson's disease. ${ }^{1,2}$ However, wound infection and dehiscence may occur in rare cases, and such infection can be very difficult to treat, with removal of the electrode leads being necessary. ${ }^{3,4}$ In 2006, we reported the usefulness of a pericranial flap for reconstruction of the dura mater. ${ }^{5}$ In 2007, intrawound continuous negative pressure and irrigation treatment (IW-CONPIT) was reported, ${ }^{6}$ after which this method has been applied to treat infected and/or intractable wounds at various sites. In 2016, the efficacy of IW-CONPIT using a closed system was reported for controlling infection of all layers of the cranium combined with cerebrospinal fluid leakage. ${ }^{7}$ We applied these methods (pericranial flap reconstruction and IW-CONPIT) in two patients with wound infection after implantation of DBS systems (Medtronic Inc., Minneapolis, Minnesota, United States), allowing infection to be managed without removal of the electrode leads so that DBS therapy could subsequently be continued ( - Table $\mathbf{1}$ ).

\section{Case 1}

\section{History and Presentation}

A 61-year-old woman developed a cutaneous fistula at 6 months after surgery for placement of DBS electrodes to treat Parkinson's disease at the Neurosurgery Department of another hospital. The patient was referred to our department because the fistula persisted. At initial examination, a cutaneous fistula was seen in a scar on the forehead. Drainage of pus was observed, and a silicon cap for fixing the electrode was visible inside the fistula (-Fig. 1A-F).

\section{Operation}

After re-opening the wound via the previous incision line, infected granulation tissue was detected around the silicon cap and along the electrode line. The silicon cap was removed, but the electrode lead was left in situ to continue DBS therapy for Parkinson's disease ( - Fig. 1G). Debridement of the infected granulation tissue was performed and the edges of the bone defect left after component removal were smoothed ( $\mathbf{- F i g} \mathbf{1 H})$. A pedicled pericranial frontalis muscle flap was harvested from the parietal region on the healthy (right) side, and was used to cover the electrode lead and fill the dead space in the bone defect ( $\mathbf{F i g . ~ 1 I - K ) . ~ T h e ~}$ edges of the debrided fistula showed very poor circulation. Because the pericranial flap was placed under the fistula, there was no bone exposure; hence, healing by secondary intention was deemed possible and the fistula was left open without suturing (-Fig. 1L). To prevent postoperative infection, two drains were placed between the pericranial flap and the bone, and closed IW-CONPIT was initiated with saline at $2,000 \mathrm{~mL} / \mathrm{d}$ (- Fig. $\mathbf{1 L}, \mathbf{M}){ }^{6}{ }^{6}$ After conducting IW-CONPIT for 1 week, the drains were removed since there were no signs of infection.

\section{Postoperative Course}

The postoperative course was good and the fistula showed epithelialization by 2 weeks after surgery. There has been no relapse of the fistula or infection during follow-up for 1.5 years. In addition, a depression has not developed at the previous site of the fistula or at the frontalis muscle donor site, with the

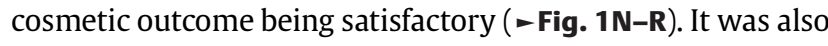
possible to continue DBS therapy for Parkinson's disease.

\section{Case 2}

\section{History and Presentation}

A 67-year-old woman with Parkinson's disease developed wound dehiscence at 4 months after surgery for implantation of DBS electrodes at another hospital. At initial examination, drainage of pus from a cutaneous fistula and exposure of a

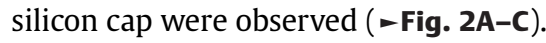

\section{Operation}

A fusiform skin incision was made to resect the cutaneous fistula, revealing that the old surgical wound was filled with infected granulation tissue (-Fig. 2D). As was done for Case 1 , the cap was removed while retaining the electrode lead. Debridement of infected granulation tissue was performed and the edges of the bone defect were smoothed. Then the wound was closed by using a bi-pedicled flap raised from the right side (-Fig. 2E-G), while the donor site was covered with a skin graft. Closed IW-CONPIT was initiated immediately after surgery ( $\mathbf{- F i g . ~} \mathbf{2 H}, \mathbf{I}$ ) and was continued for 1 week, following which the drains were removed because there were no signs of infection.

Table 1 Summary of patient characteristics and surgical interventions

\begin{tabular}{|l|l|l|l|l|l|l|l|}
\hline $\begin{array}{l}\text { Patient } \\
\text { no. }\end{array}$ & $\begin{array}{l}\text { Age } \\
\text { (y/Sex) }\end{array}$ & $\begin{array}{l}\text { Time to } \\
\text { fistula, } \\
(\mathrm{mo})\end{array}$ & $\begin{array}{l}\text { Infectious } \\
\text { agent }\end{array}$ & Primary intervention & $\begin{array}{l}\text { Secondary } \\
\text { intervention }\end{array}$ & $\begin{array}{l}\text { Duration of } \\
\text { continuous } \\
\text { irrigation } \\
\text { and negative } \\
\text { pressure }\end{array}$ & Follow-up \\
\hline 1 & $61 / \mathrm{F}$ & 6 & MRSA & $\begin{array}{l}\text { Scalp undermining and } \\
\text { pericranial flap }\end{array}$ & None & $7 \mathrm{~d}$ & 18 mo, no recurrence \\
\hline 2 & $67 / \mathrm{F}$ & 4 & MRSA & $\begin{array}{l}\text { Bi-pedicled scalp flap, } \\
\text { right-thigh split-thickness } \\
\text { skin graft }\end{array}$ & None & $7 \mathrm{~d}$ & 19 mo, no recurrence \\
\hline
\end{tabular}

Abbreviation: MRSA, methicillin-resistant Staphylococcus aureus. 

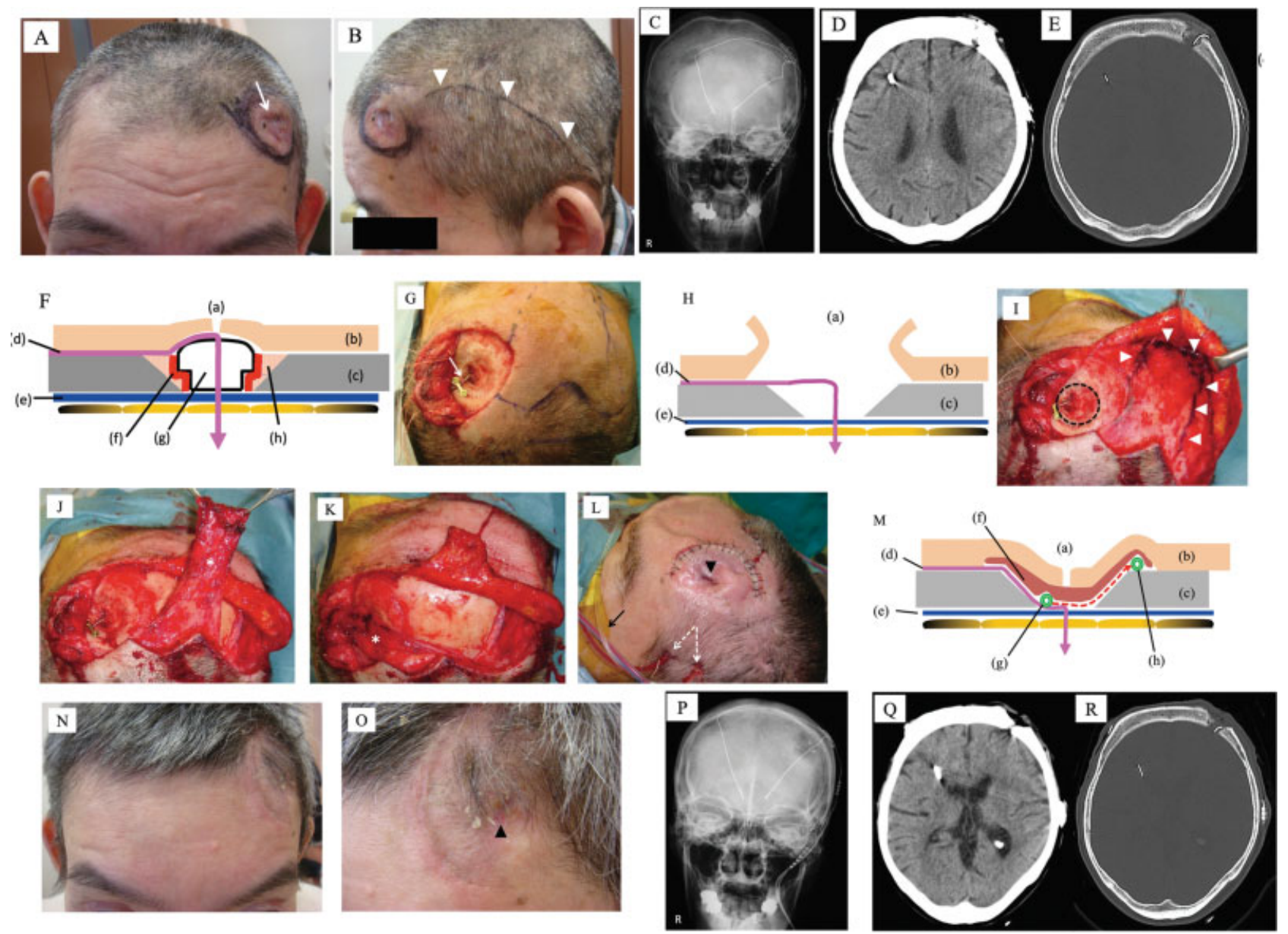

Fig. 1 Patient 1: photographs and diagram. (A) Preoperative photograph in the frontal view. Cutaneous fistula (white arrow) on the forehead draining pus. (B) Preoperative photograph in the lateral view. White arrowheads: track of the electrode lead under the skin. (C) Preoperative anteroposterior X-ray film showing the temporal and parietal electrode leads. (D) Preoperative noncontrast head computed tomography (CT) showing the temporal and parietal electrode leads. (E) Preoperative bone image CT showing the silicon cap and the burr hole. (F) Diagram of the fistula. A silicon cap for fixing the electrode lead was located just under the fistula: (a) Cutaneous fistula; (b) Scalp; (c) Bone; (d) Electrode lead; (e) Dura mater; (f) Infected granulation tissue; ( $\mathrm{g}$ ) Cap for fixing the electrode lead; (h) Bone to be removed during debridement (shaded area). (G) Intraoperative view of the DBS electrode lead fixed with a titanium miniplate and two 3-mm screws. Debridement was conducted without removing the electrode lead. To prevent scar contracture and hair loss, a zigzag incision was made in the scalp to raise the pericranial flap. Arrow: lead entering the burr hole in the cranium. $(\mathrm{H})$ Diagram after debridement of granulation tissue and smoothing of the rim of the bone defect: (a) Cutaneous fistula; (b) Scalp; (c) Bone; (d) Electrode lead; (e) Dura mater. (I) Design of the pericranial flap with a pedicle on the parietal side. White arrowheads: incision line for the flap. Black dashed circle: bone to be removed around the fistula. (J) Elevated pericranial flap. Asterisk $\left({ }^{*}\right)$ : body of the flap. (K) Covering the fistula site, electrode lead, and bone with the pericranial flap. Asterisk $\left({ }^{*}\right)$ : pericranial flap transposed over the bone defect and electrode lead. (L) Appearance at the end of surgery. Initiation of intrawound continuous negative pressure and irrigation therapy. Black arrow: irrigation tube. Dashed white arrows: suction tube. Black arrowhead: fistula left open without suturing. (M) Diagram at completion of surgery with intrawound continuous negative pressure and irrigation therapy: (a) Cutaneous fistula; (b) Scalp; (c) Bone; (d) Electrode lead; (e) Dura mater; (f) Transplanted pericranial flap; $(\mathrm{g}$ ) Irrigation tube; (h) Suction tube. Dashed red arrow: direction of saline flow. (N) Postoperative photograph in the frontal view. There is no depression at the flap donor site. (O) Postoperative photograph in the lateral view. No recurrence of infection or the fistula. Black arrowhead: completely epithelialized cutaneous fistula. (P) Postoperative anteroposterior X-ray film showing no migration or retraction of the leads. (Q) Postoperative noncontrast CT showing no intracranial hemorrhage. (R) Postoperative bone image CT showing no dead space at the fistula site.

\section{Postoperative Course}

At 1 year and 7 months after wound healing, there has been no recurrence of the fistula or infection (- Fig. 2J-L). In addition, DBS therapy has been continued for Parkinson's disease.

\section{Discussion}

Parkinson's disease is caused by degeneration of dopaminergic cells in the substantia nigra of the midbrain, with the consequent lack of dopaminergic stimulation causing motor symp- toms such as tremor, muscle rigidity, and akinesia. Anticholinergics and levodopa preparations are used as standard medical treatment, but control of symptoms such as wearing-off and dyskinesia is problematic. DBS therapy was reported by Benabid et al in 1987, ${ }^{1}$ and it is a treatment for various neurological diseases that involves electrical stimulation of the globus pallidus, thalamus, or subthalamic nucleus via implanted electrodes. In patients with Parkinson's disease, DBS therapy can be effective for akinesia and rigidity, as well as for wearing-off symptoms, and it is currently the mainstream surgical treatment for this disease. ${ }^{2}$ However, the risk of 

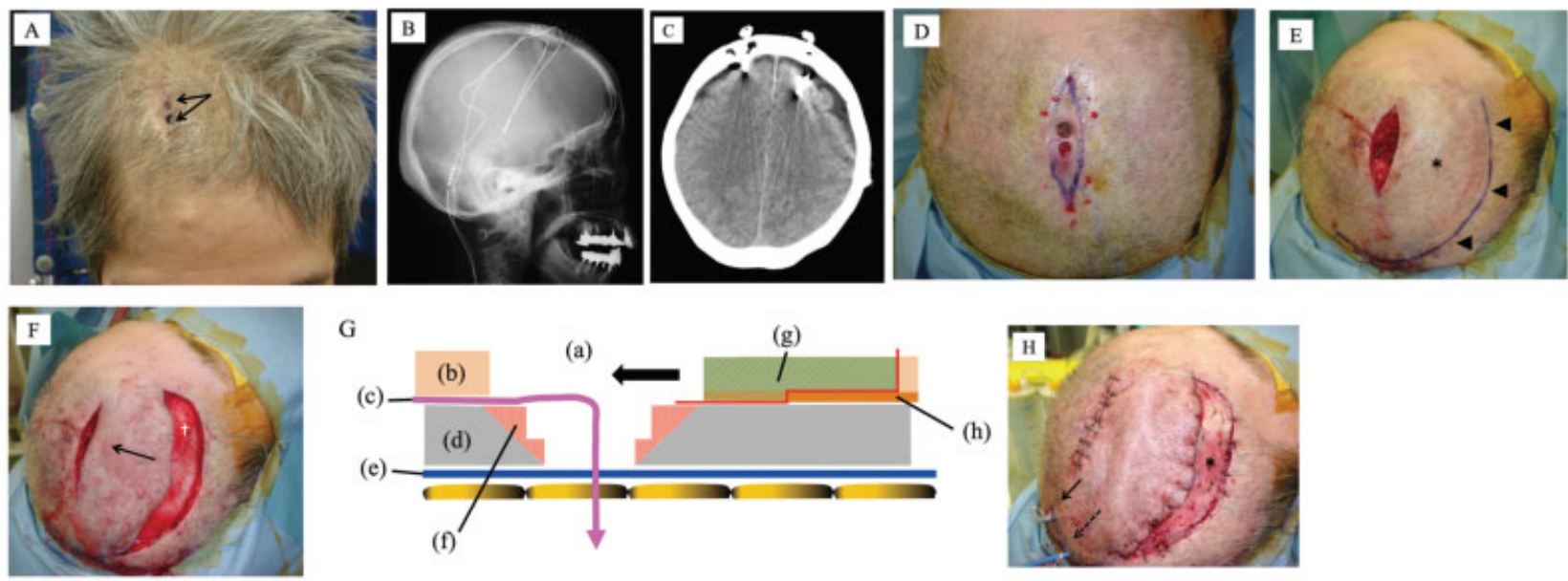

G
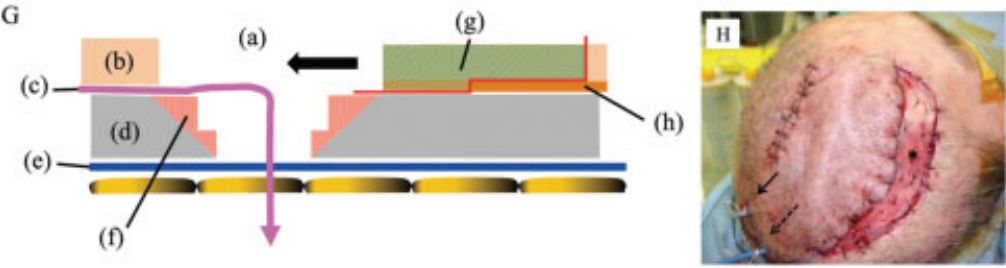

I

(i)
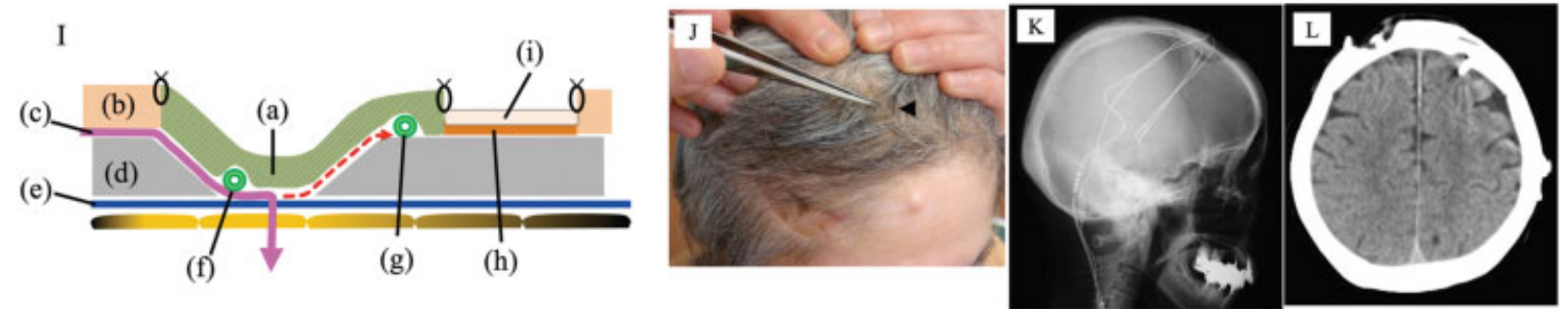

Fig. 2 Patient 2: Preoperative photographs and preoperative computed tomography (CT). (A) Preoperative photograph in the frontal view. Two cutaneous fistulae can be seen over the frontal lobe. A silicon cap for fixing the electrode lead was present under the fistula. Black arrows: cutaneous fistulae. (B) Lateral X-ray film showing the parietal electrode leads. (C) Preoperative noncontrast head CT showing the parietal electrode leads and the dead space around the silicon cap. (D) Preoperative photograph from above showing the incision line for debridement around the fistula. (E) Design of the bi-pedicled scalp flap. Black asterisk (*): body of the scalp flap. Black arrowheads: incision line for the scalp flap. (F) After transferring the bi-pedicled scalp flap. Black arrow: direction of flap movement. $\uparrow$ : pericranium; periosteum, and loose connective tissue exposed after flap transfer. (G) Diagram of the fistula site: (a) Cutaneous fistula; (b) Scalp; (c) Electrode lead; (d) Bone; (e) Dura mater; (f) Bone to be removed during debridement (red shaded area); ( $\mathrm{g}$ ) Bi-pedicled scalp flap. Black arrow: direction of flap movement. Red line: incision line for the flap; (h) Pericranium exposed by flap transfer. (H) Photograph at the end of surgery. The bi-pedicled scalp flap has been used to cover the fistula, electrode lead, and bone. Solid arrow: irrigation tube. Dotted arrow: suction tube. Asterisk (*): split skin graft on the pericranium. (I) Diagram at completion of surgery with intrawound continuous negative pressure and irrigation therapy: (a) Transplanted bi-pedicled flap covering the cutaneous fistulae; (b) Scalp; (c) Electrode; (d) Bone; (e) Dura mater; (f) Irrigation tube; (g) Suction tube. Dashed red arrow: direction of saline flow; (h) Pericranium at the flap harvest site; (i) Split skin graft. (J) Photograph at 7 months after surgery. There is no recurrence of the fistulae or infection. Black arrowhead: site where the fistulae previously existed. (K) Postoperative lateral X-ray film showing no migration or retraction of the leads. (L) Postoperative CT showing no intracranial hemorrhage and no dead space at the fistula site.

infection and exposure always exists when devices are implanted surgically. In principle, infections that do not respond to conservative treatment require removal of the implanted device, ${ }^{3,4}$ making it impossible to continue DBS therapy.

We encountered three problems when managing the patients presented here. First, wound healing was prevented by the presence of the implanted devices and infected granulation tissue. Second, there was a risk of creating dead space under the scalp if the wound was simply closed after debridement of granulation tissue. Third, it was important to retain the electrode leads for future performance of DBS, despite the intractable wound infection.

These three problems were managed as follows: First, the nonessential parts of the DBS system were removed and thorough debridement was performed. Second, the edges of the bone defect were smoothed to promote adherence of the skin flap. Then we covered the electrode lead by using a local flap such as a pericranial flap or bi-pedicled scalp flap with good blood supply. ${ }^{8}$ Flaps such as galeal, temporalis fascial, or pericranial flaps are reliable, thin, and supple, as well as having a good arc of rotation and minimal donor site morbidity. ${ }^{9}$ These flaps can also be raised in the vicinity of the operative field, which is convenient for the neurosurgeon. ${ }^{10}$ In Case 1 , we used a thin and flexible pericranial flap to fill the dead space while covering the electrode lead. In Case 2, a bi-pedicled flap with good mobility was transferred freely to broadly cover the bone defect without suturing under tension. Finally, postoperative closed IW-CONPIT was performed with a high volume of saline for infection control. ${ }^{6}$ In 1997, vacuum-assisted closure was reported as an effective method for increasing granulation tissue formation in subacute and chronic wounds. ${ }^{11}$ However, this method has no suppressive effect on wound infection. On the other hand, IW-CONPIT is designed for infected wounds and can be used to treat intractable wound infection at various sites. ${ }^{12,13}$ The key points of IW-CONPIT are reducing bacteria in the wound by continuous irrigation for 24 hours per day and elimination of dead space by negative pressure. IW-CONPIT can be supplemented by flap transplantation. In our patients, adhesion between a local flap with a good blood supply and the tissues around the fistula was 
promoted by maintenance of negative pressure using IWCONPIT, resulting in control of wound infection.

If infection occurs following implantation of a DBS device, taking these measures can make it possible to eliminate wound infection while retaining the electrode lead in situ, allowing DBS therapy to be continued.

\section{Conflict of Interest}

None.

\section{References}

1 Benabid AL, Pollak P, Louveau A, Henry S, de Rougemont J. Combined (thalamotomy and stimulation) stereotactic surgery of the VIM thalamic nucleus for bilateral Parkinson disease. Appl Neurophysiol 1987;50(1-6):344-346

2 Benabid AL, Benazzouz A, Hoffmann D, Limousin P, Krack P, Pollak P. Long-term electrical inhibition of deep brain targets in movement disorders. Mov Disord 1998;13(Suppl 3):119-125

3 Chen T, Mirzadeh Z, Lambert M, et al. Cost of deep brain stimulation infection resulting in explantation. Stereotact Funct Neurosurg 2017;95(02):117-124

4 Wetzelaer P, Vlis T, Tonge M, et al. Management of hardware related infections after DBS surgery: a cost analysis. Turk Neurosurg 2018;28(06):929-933

5 Takagi M, Kiyokawa K, Sakamoto A, et al. Two-stage reconstructive surgery of a patient with head trauma resulting in extensive cranial bone and dura mater loss caused by postoperative infection: usefulness of a pericranial flap for dura mater reconstruction. J Craniofac Surg 2006;17(03):584-590
6 Kiyokawa K, Takahashi N, Rikimaru H, Yamauchi T, Inoue Y. New continuous negative-pressure and irrigation treatment for infected wounds and intractable ulcers. Plast Reconstr Surg 2007;120(05): 1257-1265

7 Oyama M, Rikimaru H, Migita H, Sakata K, Kiyokawa K. The efficacy of continuous negative pressure and irrigation treatment inside the wound by a closed system in reconstruction of all layers of the cranium accompanying infection and cerebrospinal fluid leakage. J Craniofac Surg 2016;27(01):e10-e13

8 Staudt MD, Pourtaheri N, Lakin GE, Soltanian HT, Miller JP. Surgical management of deep brain stimulator scalp erosion without hardware removal. Stereotact Funct Neurosurg 2017;95(06):385-391

9 Horowitz JH, Persing JA, Nichter LS, Morgan RF, Edgerton MT. Galeal-pericranial flaps in head and neck reconstruction. Anatomy and application. Am J Surg 1984;148(04):489-497

10 Takumi I, Akimoto M, Hironaka K, et al. Pedicle galeo-pericranial flap augmentation in salvage frontotemporal cranioplasty: additional 'neurosurgeon-friendly' reconstruction technique of aesthetic neurosurgery in superficial temporal artery branch compromised host. Neurol Med Chir (Tokyo) 2018;58(08):350-355

11 Argenta LC, Morykwas MJ. Vacuum-assisted closure: a new method for wound control and treatment: clinical experience. Ann Plast Surg 1997;38(06):563-576, discussion 577

12 Rikimaru H, Rikimaru-Nishi Y, Yamauchi D, Ino K, Kiyokawa K. New alternative therapeutic strategy for Gustilo type IIIB open fractures, using an intra-wound continuous negative pressure irrigation treatment system. Kurume Med J, In press

13 Morinaga K, Rikimaru Y, Kiyokawa K. Treatment of abdominal surgical wound dehiscence with bowel exposure and infection: using intrawound continuous negative pressure, irrigation, and application of artificial dermis. Ann Plast Surg 2019;82(02):213-217 